\section{Developmental screening}

SIR,-It was pleasant to see my name included in the reference list of Dr D J G Bain's paper on developmental screening by general practitioners (6 August, p 363). I would, however, be even happier if I had been quoted correctly. I did not question the concept of routine surveillance. Indeed, in the summary of my paper ${ }^{1}$ I said: "It is highly desirable that every infant and young child should be examined at intervals to identify remedial defects." What I did question was the value of some of the tests carried out: "The real issue is not whether all developmental paediatric examinations are essential, but which part of the examination is." For example, I stressed the vital importance of examining every infant at about the age of 7 months for squint and hearing defects. I was therefore upset that this had been done for less than two-thirds of the children examined by the GPs in Dr Eain's series. I also made the point that developmental surveillance should be part of general practice.

Let me therefore reassure those who are interested that I am in agreement with what Dr Bain is saying. He may not have many friends in this debate. It would be folly for him to lose this one.

Stuart CARne

London W12

'Carne, S, Update, 1976, 12, 535

\section{Vision screening in preschool children}

SIR,-It is a matter of some concern that the survey carried out by $\operatorname{Dr} D$ J G Bain (6 August, p 363) showed that general practitioners holding developmental screening clinics omitted a test for visual acuity in $30 \%$ of the $4 \frac{1}{2}$-year-old children, not to mention omitting a specific test for squint in $70 \%$. It is a reasonable presumption that general practitioners who do not hold developmental screening clinics would not be as active in this way as those who do.

The Court Committee reported that in an investigation in the Newcastle area $92 \%$ of visual defects discovered at school entry had passed unnoticed up to the time of this examination. ${ }^{1}$ However, without further evidence of the prevalence of defects among those not tested and the severity of the defects undiscovered the case is not made for universal screening before school entry.

Visual defects arising just before school entry are rare. The majority are present throughout the preschool years. In many this is the most favourable period in which to treat defects. For this reason, though screening is time-consuming and the results difficult to interpret, I believe that the aim should be to discover serious defects in this age group at the earliest possible moment so that those which are treatable are treated and those which may handicap general development are known about. This does not involve testing every child. If attention is concentrated on specific groups, in addition to those with signs and symptoms, few of importance will escape. Minor defects of acuity are not of importance and it is doubtful if universal screening is worth the time spent.

In otherwise normal children these groups are the offspring of parents who had a defect arising in infancy, the siblings of children known to have a defect arising before school entry, and twins. In addition, the retarded, the brain-damaged, the deaf, and those with developmental or congenital disorders of whatever nature also need to have a definitive statement about their eyesight. If this is difficult to assess ophthalmological and orthoptic opinion should be the rule in all these children. Whether this is the responsibility of the paediatrician, the general practitioner, or the community specialists in child health is debatable, but the debate should not be an excuse for omitting tests in these groups, nor should the quest for universal screening belittle the process and lead to the abandonment of these useful priorities.

\section{Guy's Hospital,
London SE1}

P A GARDINER Committee on Child Health Services, Fit for the
Future. London, HMSO, 1976.

\section{Immersion and drowning in children}

SIR,-Referring to your leading article (16 July, p 146), which advocated central body rewarming (CBRW) using hot moist air for immersion hypothermia, the Royal National Lifeboat Institution, RAF search and rescue branch, and the Royal Navy, which jointly have the widest experience of immersion hypothermia and its treatment, have been studying for over two years the possible medical value and operational feasibility of using the soda lime/CO $\mathrm{CO}_{2} \mathrm{CBRW}$ technique. Consideration of the thermal dynamics of rewarming via the airway and the physiology of respiratory air conditioning justifies this, ${ }^{1-4}$ but the work is not yet complete and none of these rescue authorities have taken any positive decisions on the use of CBRW.

One value of CBRW would be in countering respiratory heat (and moisture) loss, which can equal or exceed $10-15 \%$ of total metabolic heat production, particularly in deeply hypothermic casualties at or below the level of shivering (core temperatures below $32-33^{\circ} \mathrm{C}$ ), whose heat production capabilities are very low. Any excess of inspired moist heat above respiratory loss would be "surplus," and although this could amount to several $\mathrm{kcal} / \mathrm{h}$, the total heat increment in CBRW is small compared with the amount which would be needed to restore normal body temperature in a deeply hypothermic casualty while in the charge of a rescue unit. However, if CBRW, with other recognised treatment, helped to prevent further depression of core temperature, including the "after-drop" during rewarming, and initiated a slow rise, even of only $1-2^{\circ} \mathrm{C}$, this would be valuable in progressively reducing the risk of ventricular fibrillation during the stressful period of casualty evacuation and increasing the chances of survival.

The precise pathways of the heat "surplus" are not yet fully understood ${ }^{5-7}$ and it has still to be determined whether there is a selective rewarming of the hypothalamus, myocardium, mediastinum, etc and what the effect of such heating would be on respiration, heat production, and the core temperature.

Soda lime $/ \mathrm{CO}_{2}$ equipment can give initial wet heat temperatures of $80-100^{\circ} \mathrm{C}$, and $\mathrm{I}$ myself twice sustained mouth burns by accidental inspiration of hot wet air at $60+{ }^{\circ} \mathrm{C}$ during early work with uncontrolled equipment. ${ }^{5}$ Upper airway tolerance of wet heat is variable. Most people find $40-45^{\circ} \mathrm{C}$ tolerable, even pleasant, but some find $45^{\circ} \mathrm{C}$ "getting hot"; at over $50^{\circ} \mathrm{C}$ it rapidly becomes un- pleasant and intolerable, and prolonged breathing at this level would undoubtedly constitute risk of damage to the upper airway. A safe and acceptable level of heat at the face mask can be obtained only by inclusion of a fail-safe device to dilute and control the hot wet air flow during the initial heat surge period. Transfer of uncontrolled wet heat to unconscious casualties would be quite unacceptable.

A medically supervised evaluation programme under rescue service (coastal/sea) conditions is scheduled to start later this year to enable the medical and operational value of CBRW to be assessed.

William J Guild

Department of Medical Physiology,

University of Edinburgh Jackson, D C, and Steinman, A M, Proceedings of the
National Academy of Sciences of the USA, 1964, N1, 1192.

McCutchan, J W, and Taylor, C L, fournal of Applied Physiology, $1951,4,121$ Applied Physiology, 1951, 4, 121.
Walker, J E C, Wells, R E, and Merrill, E W, American
fournal of Medicine, 1961, 30, 259.

Webb, P, fournal of Applied Physiology, 1951, 4, 378. Service, 1976, 62, 173 . Lloyd, E Ll, Scottish Medical fournal, 1972, 17, 83.
Lloyd, E Ll, British fournal of Anaesthesia, 1973, 45, 41 .

\section{Oestrogen therapy and endometrial} cancer

SIR,-Your leading article on this subject (23 July, p 209) cannot be allowed to pass unchallenged.

There is no doubt that the single most controversial issue related to long-term oestrogen therapy is the possible role of such medication in the aetiology and pathogenesis of breast and uterine cancer. The imprecise nature of the relevant data does not allow full definition of the risk. The value of such data has been to create an awareness of potential risks, of abuse of potent hormones, and of the urgent need for further research and to emphasize the lack of controlled prospective clinical evaluation to date. Some perspective needs to be maintained and in this respect I can aptly quote from one of your own leading articles: "What should we do now? Smoking 20 cigarettes a day increases the risk of death from lung cancer 17-fold. The risk of oestrogens is less than that."1

It is not, however, the cancer relationship I wish to challenge: rather it is your attempt to create controversy where none really exists. This concerns the use of oestrogens for the short-term relief of menopausal symptoms. The paper you referred to by Mulley and Mitchell $^{2}$ was merely a published opinion based on no direct research and a less than adequate knowledge of the existing literature. It was criticised in the correspondence columns of the Lancet. The only specific early symptoms of oestrogen deficiency are those related to hot flushes and atrophic vaginitis. ${ }^{3}$ In turn they have been shown to respond to short-term oestrogen therapy as tested on single-blind oestrogen-placebo crossover studies, ${ }^{4}$ double-blind studies, ${ }^{56}$ in innumerable clinical reports over many years, and in the vast clinical experience. Moreover, the "mental tonic" effect of oestrogens described by myself ${ }^{7}$ has been confirmed by Campbell and Whitehead ${ }^{56}$ and by Furuhjelm and Fedor-Frejbergh. ${ }^{8}$

Your question "What should we do now ?" can therefore be answered. Until specific answers are forthcoming we can keep an open 